\title{
Elaboración de un platillo utilizando como base un producto ancestral: El Pulque
}

\author{
Elaboration of a dish using as a base an ancestral product: Pulque
}

\section{Erika Vianey Silva Gamero ${ }^{a}$ Juan Ramírez Godinez b , Jair Emmanuel Onofre Sánchez c}

\begin{abstract}
:
This work seeks to highlight the use of pulque in an everyday product: a pancake. Pulque is a drinky drink that is obtained from the fermentation of mead, which is extracted from the maguey and left to rest in a tinacal for its fermentation.
\end{abstract}

Keywords:

Maguey, Pulque, Drink, Tinacal

Resumen:

Éste trabajo busca resaltar el uso del pulque en un producto cotidiano: un panqué. El pulque es una bebida embriagante que se obtiene de la fermentación del aguamiel, el cual se extrae del maguey y se deja reposar en un tinacal para su fermentación.

\section{Palabras Clave:}

Maguey, Pulque, Bebida, Tinacal

\section{Introducción}

Del náhuatl octli (bebida embriagante), el pulque se obtiene de la fermentación del aguamiel, el cual el tlachiquero extrae con ayuda de un acocote del maguey pulquero o agave salmiana. Hace varios cientosde años era una bebida que se reservaba a las clases altas de la antigua sociedad azteca, quienes lo usaban en rituales y festejos que realizaban en honor a Mayahuel, la diosa del maguey. En tiempos prehispánicos, solamente podían consumir pulque las personas mayores de los 52 años de edad. A los que iban a ser sacrificados en el templo de Huitzilopochtli se les permitía beberlo hasta embragarse. Así mismo, era considerado un remedio medicinal muy eficaz contra los males más variados. ${ }^{2,3}$

El principal reto al que se enfrentan los productores de pulque hoy en día es a contrarrestar la mala imagen que la industria Cervecera dio sobre ellos, ya que hicieron ver al pulque como una bebida nociva para la salud, cuando es todo lo contrario. ${ }^{5}$

La llamada "Bebida de los dioses" es un producto nutritivo que forma parte de la tradición mexicana, tomado con moderación funciona como un complemento alimenticio por su contenido de proteínas y vitaminas $\mathrm{C}$ y del complejo B. Además, cuenta con propiedades medicinales, como: protección de la flora intestinal, actúa como diurético, reduce el insomnio y combate la

\footnotetext{
a Autor de Correspondencia, Estudiante de la Licenciatura de Gastronomía, Universidad Autónoma del Estado de Hidalgo, https://orcid.org/0000-0001-5121-0639, Email: si318939@uaeh.edu.mx

${ }^{\text {b }}$ Profesor investigador adscrito a la Licenciatura en Gastronomía de la Universidad Autónoma del Estado de Hidalgo, Instituto de Ciencias Económico - Administrativas, https://orcid.org/0000-0001-7718-0546, Email: juan_ramirez@uaeh.edu.mx
}

c Profesor investigador adscrito a la Licenciatura en Gastronomía de la Universidad Autónoma del Estado de Hidalgo, Instituto de Ciencias Económico - Administrativas, https://orcid.org/0000-0002-9484-8947, Email: jair_onofre6570@uaeh.edu.mx 
anemia. El pulque es una bebida especial que debemos apreciar por nuestra historia. ${ }^{4}$

\section{Desarrollo}

a) Objetivo general de la práctica:

Realizar una preparación culinaria investigando el proceso de elaboración del pulque, para mostrar su relevancia en la gastronomía mexicana.

b) Instrumentos necesarios:

Batidora, espátula, báscula, horno, bowls, molde pequeño para bundt cake.

c) Nombre de la Práctica

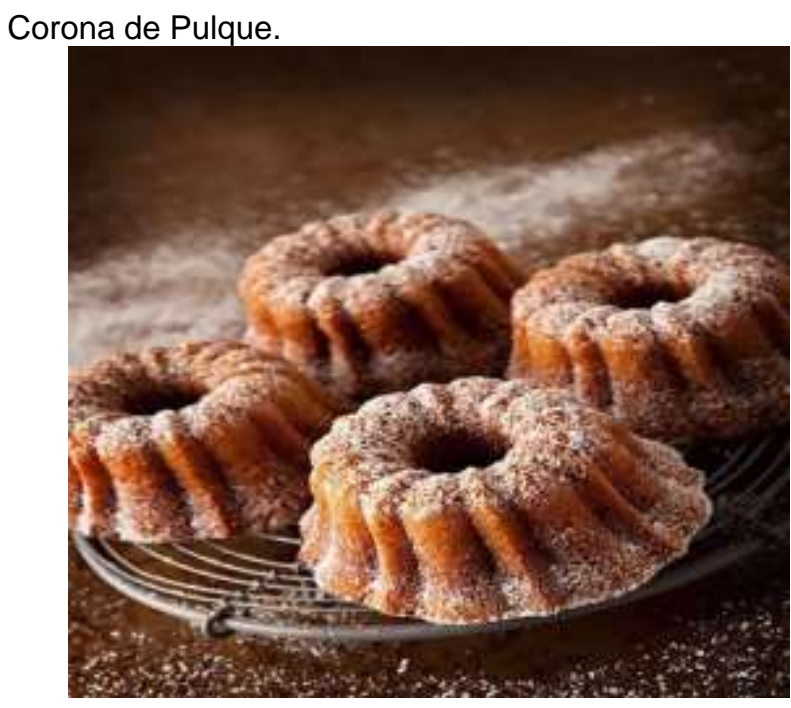

Ilustración 1: Mini Bundt cake. ${ }^{1}$

Insumos requeridos para su realización

Tabla 1. Insumos para realizar la corona de pulque.

\begin{tabular}{l|c|c|}
\cline { 2 - 3 } \multicolumn{1}{l|}{ Ingredientes } & Cantidad & Unidad \\
\hline Pulque & 0.200 & $\mathrm{~L}$ \\
\hline Azúcar & 0.033 & $\mathrm{Kg}$ \\
\hline Harina & 0.250 & $\mathrm{Kg}$ \\
\hline Manteca de & 0.015 & $\mathrm{Kg}$ \\
cerdo & & $\mathrm{Kg}$ \\
\hline Nueces & 0.030 & $\mathrm{Kg}$ \\
\hline Pasas & 0.015 & $\mathrm{Kg}$ \\
\hline Huevo & 0.100 &
\end{tabular}

d) Procedimiento

Mise en place

1. Pesar correctamente los ingredientes.

2. Enharinar los moldes y reservar.

Procedimiento

1. Acremar la manteca de cerdo, agregar el azúcar poco a poco.

2. Agregar los huevos y el pulque, hasta obtener una consistencia cremosa.

3. Mezclar con los frutos secos.

4. Incorporar la mezcla en los moldes y dejar reposar por 12 horas o hasta doblar su tamaño.

5. Hornear a $180^{\circ} \mathrm{C}$ por 25 minutos.

6. Dejar enfriar por 10 minutos y desmoldar.

\section{Conclusión}

Como resultado, tenemos un postre con una miga suave y un sabor predominante en el cual se puede apreciar la presencia de los frutos secos y la intensidad del pulque gracias al tiempo de fermentación en el cual dejamos actuar las levaduras, por ello, el olor es dulce y delicado.

\section{Referencias}

[1] Luna, M. (s.f.). Pinterest. Obtenido de Pinterest https://www.pinterest.com.mx/pin/283656476503925131/

[2] Pesquera, S. d. (10 de abril de 2018). Gobierno de México. Recuperado el 12 de agosto de 2021, de Gobierno de México: https://www.gob.mx/siap/articulos/maguey-pulquer (Luna)?idiom=es

[3] Rural, S. d. (15 de septiembre de 2016). Gobierno de México. Recuperado el 12 de 08 de 2021, de Gobierno de México: https://www.gob.mx/agricultura/es/articulos/pulque-una-delicia-mitica

[4] Rural, S. d. (27 de septiembre de 2018). Gobierno de México. Recuperado el 12 de 08 de 2021, de Gobierno de México: https://www.gob.mx/agricultura/es/articulos/el-pulque-mas-que-tradicion- espura-nutricion-176177

[5] Rural, S. d. (28 de septiembre de 2019). Gobierno de México. Recuperado el 12 de 08 de 2021, de Gobierno de México: https://www.gob.mx/agricultura/es/articulos/la-magia-detras-de-laproduccion-del-pulque?idiom=es 